\title{
Alcohol-related Rape Cases: Barristers' Perspectives on the Sexual Offences Act 2003 and Its Impact on Practice
}

\author{
Clare Gunby,* Anna Carline ${ }^{\dagger}$ and Caryl Beynon ${ }^{\ddagger}$
}

\begin{abstract}
This article discusses the findings of a qualitative study which interviewed 14 barristers about the law-in-action reality of rape cases involving alcohol intoxication. The study aimed to identify how a number of provisions introduced by the Sexual Offences Act 2003 were perceived by barristers, worked in practice and their overall impact in terms of improving the law of rape and specifically, alcohol-involved rape. The article focuses on barristers' opinions relating to the definition of consent as contained in s. 74; the 'consent presumptions', with specific emphasis on s. 75(2)(f); the jurors' perceived response to jury directions and definitions; and barristers' opinions on the need for future reforms in this area. It is argued that certain provisions introduced by the 2003 Act are not always utilised in a way that was intended, have been interpreted and applied narrowly and, in a number of instances, fail to assist the jury.
\end{abstract}

Keywords Rape; Consent; Capacity; Intoxication; Sexual Offences Act 2003

Over the last 10 years, the offence of rape has become a major social and political issue within England and Wales. Within the first quarter of 2010 two major studies have been published which explore public perceptions regarding rape and also the contention that the criminal justice system is in some way failing to secure justice for those who are victims of this crime. ${ }^{1}$ Concerns are frequently expressed in relation to the conviction rate being unduly low, and suggestions with regards to how the system could be improved are frequently aired. ${ }^{2}$ Of particular note are issues relating to intoxication and rape, especially cases in which the complainant was voluntarily and exceptionally intoxicated at the time of the incident. Research studies indicate that many people are reluctant to believe a woman who states she was raped when voluntarily intoxicated or alternatively hold her in some way blameworthy

* Centre for Public Health, Research Directorate, Liverpool John Moores University; e-mail: c.gunby@2008.ljmu.ac.uk.

† School of Law, Liverpool John Moores University; e-mail a.carline@ljmu.ac.uk.

$\ddagger$ Centre for Public Health, Research Directorate, Liverpool John Moores University; e-mail: c.m.beynon@ljmu.ac.uk.

1 Opinion Matters, Wake Up to Rape Research Summary Report (Opinion Matters: London, 2010) prepared for the Havens (Sexual Assault Referral Centres); Baroness Stern, The Stern Review: A Report by Baroness Vivien Stern CBE of an Independent Review into How Rape Complaints Are Handled by Public Authorities in England and Wales (Government Equalities Office and the Home Office: London, 2010).

2 See Baroness Stern, ibid.

The Journal of Criminal Law (2010) 74 JCL 579-600 
and are therefore unwilling to convict the accused. ${ }^{3}$ From a strictly legal perspective, however, the key issue should remain whether the complainant consented to the sexual intercourse.

This article draws upon interviews with barristers in order to generate knowledge and insights into the law-in-action reality of rape cases involving intoxication. In particular, the article will analyse barristers' opinions relating to the definition of consent as contained in s. 74 of the Sexual Offences Act 2003 (hereafter 'the 2003 Act'); the 'consent presumptions', with specific emphasis on s. 75(2)(f); and also barristers' opinions on the need for future reforms in this area. The analysis will unfold over six sections. The following section will discuss the rationale behind, and the methodology of, the research project. This will include a discussion of the key legal issues; an overview of the interview schedule and a brief demography of the study participants. Discussion of the study findings will take place over sections 2 to 5 of the article. Section 2 will focus on the definition of consent as contained in s. 74 with particular emphasis placed on the meaning and interpretation of 'capacity'. Barristers' opinions on the relevant 'consent presumptions' will be examined in section 3. Section 4 will discuss issues relating to jury directions and jury behaviour and participants' perceptions on the need for future legal reform will be explicated in section 5. In conclusion, the article will argue that the opinions of those who practise the law on a daily basis clearly indicate that not only have the reforms introduced by the 2003 Act done little to improve the offence of rape, but that further reform is considered in the least unnecessary, and at the most, detrimental. This outcome reinforces the opinions expressed by Baroness Stern and the suggestion that more needs to be done within the system to support victims of rape. ${ }^{4}$

\section{The law, the rationale and the methods: exploring barristers' opinions on rape and the 2003 consent provisions}

The 2003 Act represented the first major overall reform of sexual offences in 50 years. As recognised by the 2003 Act, of particular concern to the offence of rape is the issue of consent, due to its pivotal role within both the actus reus and mens rea of the crime. Prior to the 2003 Act, consent was not statutorily defined, but was rather governed by the common law. ${ }^{5}$ The previous Labour government (hereafter 'the government') expressed concerns about this position as well as expressing concern more generally with regard to the low conviction rate for rape, in particular, the fact that it had fallen from 25 per cent in 1985 to

3 See, e.g., Opinion Matters, above n. 1; E. Finch and V. Munro, 'Juror Stereotypes and Blame Attribution in Rape Cases Involving Intoxicants: The Finding of a Pilot Study' (2005) 45 British Journal of Criminology 25; E. Finch and V. Munro, 'The Demon Drink and the Demonized Woman: Socio-Sexual Stereotypes and Responsibility Attribution in Rape Trials Involving Intoxicants' (2007) 16(4) Social $\theta$ Legal Studies 591.

4 See Baroness Stern, above n. 1.

5 See especially $R$ v Olugboja [1981] 3 WLR 585. 
7 per cent in $2000 .^{6}$ Indeed, the White Paper Protecting the Public specifically stated that it is vital that the law is as clear as possible about what consent means in order to prevent miscarriages of justice . . ${ }^{7}$ To this end, s. 74 of the 2003 Act defined consent for the first time stating: 'A person consents if he agrees by choice and has the freedom and capacity to make that choice'. However, the extent to which the definition as contained in s. 74 meets the stated objective of being 'clear and unambiguous' has been queried by commentators. ${ }^{8}$ Notably, Temkin and Ashworth have argued that the words 'freedom' and 'capacity': 'raise philosophical issues of such complexity as to be ill-suited to the needs of criminal justice, all the questions about how much liberty of action satisfies the definition remain at large' ${ }^{9}$

\section{'A drunken consent is still consent': intoxication, capacity to consent and s. 74}

The issue of having the 'capacity' to consent is particularly relevant to rape cases involving intoxication where alcohol and/or drugs may sufficiently impact on an individual's capacity to choose to have sex. The problems faced by the prosecution in cases involving voluntary intoxication and consent were brought into the public domain by the case of Dougal. ${ }^{10}$ Here the judge directed the jury to acquit after being informed by the prosecution that they could not proceed any further with the trial 'because it was unable to prove that the complainant had not given consent because of her level of intoxication'. ${ }^{11}$ Whilst issues of capacity and levels of intoxication were not directly addressed by the court, the Office for Criminal Justice Reform considered that such matters 'could quite properly have been put forward to a jury and the matter left for them to decide whether or not the complainant's level of drunkenness had meant that she was not capable of consenting to the sexual activity $^{\prime} .{ }^{12}$ Consequently, the Office for Criminal Justice Reform consulted on, amongst other issues, whether the word 'capacity' should be defined within the legislation.

The relevant parliamentary debates in relation to the 2003 Act clearly indicate that capacity is concerned primarily with age and mental disability as opposed to voluntary intoxication. ${ }^{13}$ In the 2006 Consultation Paper, reference is made to the common law definition: 'A complainant will not have had the capacity to agree by choice where their understanding and knowledge were so limited that they were not in a position

6 Home Office, Protecting the Public: Strengthening Protection against Sex Offenders and Reforming the Law of Sexual Offences (Home Office: London, 2002) para. 10.

7 Ibid. at para. 28.

8 Ibid. at para. 30 .

9 J. Temkin and A. Ashworth, 'The Sexual Offences Act 2003: (1) Rape, Sexual Assaults and the Problems of Consent' [2004] Crim LR 328 at 336.

$10 R$ v Dougal, unreported, 24 November 2005, Swansea Crown Court.

11 Cited in Office for Criminal Justice Reform, Convicting Rapists and Protecting VictimsJustice for Victims of Rape: A Consultation Paper (Office for Criminal Justice Reform: London, 2006) 13.

12 Ibid.

13 See, in particular, the House of Lords Debates on the Act: Hansard, HL, vol. 648(95), cols 593-596, 19 May 2003. 
to decide whether or not to agree' ${ }^{14}$ By focusing on the issues of 'understanding' and 'knowledge' this definition is overtly concerned with issues of mental disability and age. Nevertheless, such a definition could also apply to cases involving intoxication where it is clear that the complainant was so drunk that whilst they were not unconscious, they were not fully aware of what was happening. Numerous respondents to the consultation favoured this approach whereas others favoured that contained in s. 30(2) of the 2003 Act:

(a) he lacks the capacity to choose whether to agree to the touching (whether because he lacks sufficient understanding of the nature or reasonably foreseeable consequences of what is being done, or for any other reason), or

(b) he is unable to communicate such a choice to A.

Those respondents in favour of this later definition argued that it is clear and easy to understand and would cover the circumstances where a complainant was so drunk-but not unconscious-as to not know what was happening or unable to say no'. ${ }^{15}$ However, other respondents argued that a capacity definition may actually hinder rather than help the prosecution and 'make it more difficult to pursue a case'. ${ }^{16}$

Prior to the publication of the government's response to the consultation, the Court of Appeal explicitly dealt with the issue of voluntary intoxication, consent and capacity in the case of Bree. ${ }^{17}$ Here the accused was initially convicted for rape after engaging in sexual intercourse with a complainant who was voluntarily intoxicated. The Court of Appeal, however, quashed his conviction due to the trial judge's inadequate jury directions, commenting that:

the jury should have been given some assistance with the meaning of 'capacity' in circumstances where the complainant was affected by her own voluntarily induced intoxication, and also whether, and to what extent they could take that into account in deciding whether she had consented. ${ }^{18}$

Referring to the case of Dougal, the Court of Appeal notes that 'a drunken consent is still a consent' and that under s. 74 the issue is whether the complainant 'has temporarily lost her capacity to choose whether to have intercourse'. ${ }^{19}$ If this is so, she is not consenting. The court further comments that 'capacity to consent may evaporate well

14 Judge P. Rook QC and R. Ward CBE, Rook $\theta$ Ward on Sexual Offences: Law $\theta$ Practice (Sweet \& Maxwell: London, 2004) paras 1.81-1.94, cited in Office for Criminal Justice Reform, above n. 11 at 13.

15 Office for Criminal Justice Reform, Convicting Rapists and Protecting Victims-Justice for Victims of Rape: Response to Consultation (London: Office for Criminal Justice Reform, November 2007) 9.

16 Ibid. at 10.

$17 R$ v Bree [2007] 2 Cr App R 13. For a critical analysis of the Bree judgment, see, e.g., S. Cowan, 'The Trouble with Drink: Intoxication, (In)Capacity, and the Evaporation of Consent to Sex' (2009) 41 Akron Law Review 899; P. Rumney and R. Fenton, 'Intoxicated Consent in Rape: Bree and Juror Decision-making' (2007) 71 MLR 279; S. Wallerstein, 'A Drunken Consent is Still Consent-or Is It? A Critical Analysis of the Law on a Drunken Consent to Sex Following Bree' (2008) 73 JCL 318.

$18 R$ v Bree [2007] 2 Cr App R 13 at [39].

19 Ibid. at [32]. 
before a complainant becomes unconscious', ${ }^{20}$ but emphasises that such an issue is 'fact-specific' and thus it is not appropriate to 'create some kind of grid system which would enable the answer to be related to some prescribed level of alcohol consumption', noting that people react differently to alcohol and an individual's tolerance is by no means consistent. ${ }^{21}$ Overall, it is argued that: 'the practical reality is that there are some areas of human behaviour which are inapt for detailed legislative structures'.22 Thus, it is a question of fact for the jury to consider whether the complainant was, due to her voluntary intoxication, incapable of consenting.

Drawing upon the judgment in Bree, the government decided against introducing a statutory definition of 'capacity' stating that the Court of Appeal 'provided vital guidance on how the law in this area should operate'. ${ }^{23}$ It is thus considered that the statement with regard to whether the complainant has temporarily lost her capacity to choose whether to have intercourse on the relevant occasion' is sufficient. However, it can be argued that this fails to provide the jury with any guidance as to the meaning of the word 'capacity', a factor that is pivotal in cases involving voluntary intoxication, especially in the absence of a rebuttable presumption.

\section{Presuming rape? The consent presumptions in ss 75-76 of the Sexual Offences Act 2003}

The consent presumptions introduced by the 2003 Act are perhaps one of the most radical amendments in relation to the law of consent. The government in Protecting the Public maintained that the rationale behind the presumptions:

... is to strike the right balance between protecting victims and ensuring fairness under the law for defendants by helping juries with the fundamental questions of whether the victim was able to, and did in fact, give his or her consent on the occasion in question. ${ }^{24}$

Section 75 of the 2003 Act provides a number of rebuttable presumptions with regard to consent. If there is evidence of certain factors, then it will be presumed that the complainant did not consent and also that the defendant did not have a reasonable belief in consent. In such a situation a burden is placed on the defence to rebut this presumption.

Proving lack of consent is one of the biggest challenges for the prosecution and, with rape convictions at an all-time low, the presumptions were introduced in the hope that they would remedy this situation..$^{25}$ The presumptions contained in $\mathrm{s} .75$ are considered to represent those situations in which most people would agree that consent was not

20 Above n. 18 at [34].

21 Ibid. at [35].

22 Ibid.

23 Office for Criminal Justice Reform, above n. 15 at 10.

24 Home Office, above n. 6 at para. 32.

25 Home Office, Setting the Boundaries: Reforming the Law on Sexual Offences, Volume One (Home Office: London, 2002) 9; House of Commons Home Affair Committee, The Sexual Offences Bill: Fifth Report of Session 2002-3 (TSO: London, 2003) 6. 
present. They include, as one would expect, the use of or threats of violence. With regard to alcohol and intoxicated rapes, the relevant presumptions are: s. 75(2)(d): 'the complainant was asleep or otherwise unconscious at the time of the act'; and s. 75(2)(f): 'any person had administered to or caused to be taken by the complainant, without the complainant's consent, a substance which, having regard to when it was administered or taken, was capable of causing or enabling the complainant to be stupefied or overpowered at the time of the relevant act'.

As initially drafted, the presumptions were intended to place a persuasive burden on the defendant. This would require the defence to convince the jury that, on the balance of probabilities, despite the circumstances the complainant did indeed consent and that his belief in consent was reasonable. However, the proposal to place a persuasive burden on the defendant was met with fierce opposition as it was considered to contravene the presumption of innocence and tip the balance too far in favour of complainants. ${ }^{26}$ Hence, the end result is less radical than was initially proposed as it is now only necessary that the defence raise sufficient evidence to convince the judge that there is an issue with regard to consent. ${ }^{27}$ In contrast, the s. 76 presumptions are conclusive and therefore only apply in a very narrow set of circumstances involving deception. ${ }^{28}$

During the 2006 consultation, numerous respondents agreed that s. 75(2)(d) should be reformed to read as follows: 'Where a person was asleep, unconscious or too affected by alcohol or drugs to give free agreement'. However, the Home Office decided against this approach due to the fear of 'mischievous accusations'.$^{29}$ The myth of false allegations being commonplace has become a truth in relation to rape and sexual assaults with research indicating that people believe women are more likely to lie about being raped when they have been drinking. ${ }^{30}$ Significantly, however, such beliefs are not substantiated by empirical statistics whilst commentators also argue that the percentage of false rape allegations is consistent with the level of false allegations found across other crimes. ${ }^{31}$ Despite the government's rejection of the modification to presumption s. 75(2)(d), it is still somewhat unclear whether such an amendment would be a useful advancement to the law which would help in the prosecution of alcohol-related rapes.

As a consequence of the issues raised above, the current research study aimed to gain insights into barristers' experiences, perspectives and attitudes towards the changes made to the offence of rape, and consent in particular, brought in by the 2003 Act. Because barristers deal with the law on a practical and daily level, it was rationalised that they are best placed to assess whether the 2003 Act has been successful in its

26 See Temkin and Ashworth, above n. 9 at 343.

$27 R$ v Zhang [2007] EWCA Crim 2018.

$28 R$ v Jeetha [2007] 2 Cr App R 34.

29 Office for Criminal Justice Reform, above n. 11 at 128.

30 See Opinion Matters, above n. 1; Finch and Munro, 'Juror Stereotypes' above n. 3 and Finch and Munro, 'Demon Drink' above n. 3.

31 See the discussion in P. Rumney, 'False Allegations of Rape' (2004) 65(1) Camb LJ 125. 
stated aim of improving and clarifying the law. Moreover, there was a specific interest in exploring whether practitioners felt that further reform was both necessary, and potentially productive, due to the relatively recent (albeit now abandoned) proposals to reform this area. ${ }^{32}$ Prior to the current research, the only studies to have analysed the opinions of barristers were undertaken prior to the enforcement of the 2003 Act. ${ }^{33}$ Consequently, this is the first research to date to analyse barristers' perspectives on the consent provisions contained in the 2003 Act and also ask questions specifically on intoxication, thus providing original and invaluable insights into this area of law.

\section{Method: recruitment and population}

Barristers were recruited to the research study via initial liaison with a local circuit judge who became involved in the project at an early stage. The judge was licensed to try rape cases and had extensive experience of residing over sexual offence trials in the study district. He consequently provided the details of two legal contacts that were suitably placed to suggest appropriate advocates to approach for interview. Twenty-one barristers were initially contacted; all being sent letters explaining the nature of the study along with an invitation to be interviewed. Those barristers that did not initially respond were sent at least one further letter or e-mail reminding them about the study. Of the 21 barristers approached, 14 agreed to be interviewed. All interviews took place at the barrister's chambers or Crown Prosecution Service premises and were conducted between 3 June 2009 and 19 January 2010. All barristers gave generously of their time with interviews lasting a minimum of one hour and up to an hour and 45 minutes.

The study population consisted of 14 barristers (10 males and 4 female) who were all practising within the North West region of England. This male to female split was roughly representative of the gender make-up of criminal barristers working across the major chambers in the study area (this observation is based on analysis of the members lists reported on the websites of the chambers from which barristers were selected). Barristers were recruited from five chambers and the Crown Prosecution Service. All were at different points in their career with the number of years of experience ranging from 7 to 34 , with a mean of 19.4 years. The majority of barristers could be classified as highly experienced; five were grade four prosecutors and two sat as recorders. All barristers had been in practice prior to the 2003 Act and had either knowledge or direct experience of trying rape under the pre-2003 law, placing them in a suitable position to draw comparisons, highlight improvements and articulate possible failings with the new legislation. Twelve advocates had experience of prosecuting and defending rape cases whilst barrister 8 and 14 only had experience of defending, due to their more junior status. Whilst the study sample cannot be viewed as

32 Office for Criminal Justice Reform, above n. 11 and n. 15.

33 J. Temkin and B. Krahe, Sexual Assault and the Justice Gap: A Question of Attitude (Hart Publishing: Oxford and Portland, Oregon: 2008). 
representative of the entire barrister population involved in rape cases, it does draw together a broad range of experience enabling important issues and insights to be gained in relation to rape cases involving intoxication and the 2003 Act.

\section{Method: research design and analysis}

Qualitative data collection took place through the use of a semistructured interview schedule. Schedule questions addressed how a number of the provisions introduced by the 2003 Act were perceived by advocates, how they worked in practice and their overall impact in relation to improving the law of rape. The interview schedule specifically addressed the definition of consent; the directions provided to jurors in helping them to understand the notion of consent; and also the change in relation to the mens rea of rape. Barristers were specifically questioned on alcohol-involved rape cases, including the difficulties inherent in trying such cases and how jurors were assisted with the meaning of 'capacity to consent'. Questions concerning the need to define capacity in legislation were also asked. Opinions were further sought on the consent presumptions contained in s. 75 and s. 76 of the 2003 Act, with particular focus on s. 75(2)(f). These questions included the frequency with which the presumptions were used, the situations covered by s. 75(2)(f) and how the terms of this presumption had come to be interpreted in practice. With regard to reform, barristers were asked about the benefits/disadvantages of an additional evidential presumption that covered the circumstance of extreme drunkenness; and the need for any further legal reform in the area of voluntary intoxication and rape.

The interview schedule was devised following a review of the relevant literature. Due to the small amount of empirical research that has directly explored this area of the law, a number of issues and concerns raised in government Consultation Papers and ideas expressed in case commentaries were used to help formulate the schedule. ${ }^{34}$ The final version of the schedule was sent to the liaison judge for comment and feedback before the first interview took place.

Interviews were digitally recorded and transcribed immediately after they had been conducted. This enabled the identification of additional lines of inquiry which the researchers pursued in subsequent interviews. ${ }^{35}$ The barrister transcripts were independently scrutinised by the two primary investigators in order to identify broad themes; these were coded using NVivo qualitative data analysis software and were discussed and agreed by the investigators to ensure there was consistency in their

34 E. Finch and V. Munro, 'The Sexual Offences Act 2003: Intoxicated Consent and Drug Assisted Rape Revisited' [2004] Crim LR 789; E. Finch and V. Munro, 'Juror Stereotypes', above n. 3; E. Finch and V. Munro, 'Breaking Boundaries? Sexual Consent in the Jury Room' (2006) 26(3) Legal Studies 303; Office for Criminal Justice Reform, above n. 11; Office for Criminal Justice Reform, above n. 15; V. Tadros, 'Rape Without Consent' (2006) 26(3) OJLS 515; Temkin and Ashworth, above n. 9.

35 A. Strauss and J. Corbin, Basics of Qualitative Research: Grounded Theory, Procedures and Techniques (Sage: London, 1990). 
allocation. Transcripts were reread by both parties and passages that related to the same theme were grouped together; within each major theme additional sub-themes emerged. When disparities arose in relation to the grouping process these issues were rectified through discussion and eventual consensus. Although several major themes emerged throughout the analysis, those that will be considered here are 'capacity to consent', 'consent presumptions', 'jury behaviour' and 'the need for further reform'.

\section{2. (In)capacity to consent: $s$. 74 and voluntary intoxication}

As stated, the issue of capacity to consent has proven to be central to rape cases in which the complainant, and frequently the accused, were voluntarily intoxicated. Whilst a consent presumption exists to deal with the phenomena of 'drink spiking' or 'drug-assisted rape', no such provision currently exists for cases involving voluntary intoxication. As such, the prosecution must rely on the definition of consent as contained in s. 74 and must therefore prove beyond a reasonable doubt that the complainant did not consent to sexual intercourse and that the defendant did not hold a reasonable belief in consent. Significantly, the Act does not provide further explanation as to the meaning of 'capacity' within s. 74 and neither is such detail provided to the jury by virtue of a Judicial Studies Board direction. In light of these issues and also the concerns expressed by commentators with regard to the ambiguity of the notion of 'capacity', especially in cases involving intoxication, ${ }^{36}$ barristers were directly asked how jurors were assisted in interpreting the point at which a complainant lost the capacity to consent and whether capacity should be defined in law. In the construction of the capacity theme the possible advantages and disadvantages of a legal definition were analysed along with the frequency with which the 'incapacity to consent' line of argument was used at trial.

\section{Assisting the jury with (in)capacity: the need for a legal definition?}

Where the prosecution's case was based on the argument that the complainant was conscious but too drunk to have had the capacity to consent to sex, several barristers stated that the judge would provide the jury with 'assistance' (barrister 10) in order to help contextualise what 'capacity' meant. It was argued that jurors' attentions would be drawn to factors which related to different individual's tolerance to alcohol, judges may also emphasise that even if an individual is drunk, this does not inevitably impact on their ability to choose and would highlight that 'drunken consent is still consent' (barrister 10). It may be suggested that such directions echo the judgments made in the cases of Bree and Dougal and are being drawn upon by certain judges in an attempt to assist the jury. Other advocates, however, argued that it was more frequently the

36 See Cowan, above n. 17 and J. Elvin, 'Intoxication, Capacity to Consent, and the Sexual Offences Act 2003' (2008) 19 Kings Law Journal 151. 
case that directions would simply involve outlining what the complainant had drank and describing the behaviours attributed to her by the other witnesses in the case. Judges were reported to then tell the members of the jury to draw their conclusions based on this accumulation of evidence. Moreover, it was clear that there was some confusion amongst advocates as to whether a specimen direction on the capacity to consent when parties were intoxicated existed: whilst certain advocates suggested it did, other stated that it did not. It is worth noting at this point that there was additional confusion around the specific circumstances that were covered by the evidential and conclusive presumptions. Whilst this will be discussed further below, this ambiguity may reflect a general confusion around these specific areas of the law. It may also link to a point raised by the Home Office stocktake that suggested there had been insufficient publicity around the 2003 Act and its provisions resulting in knowledge gaps amongst criminal justice practitioners. ${ }^{37}$

The majority of barristers did not feel that capacity should be defined in legislation arguing that it would not assist the jury further and that the law had probably already gone as far as it could in relation to this area. Indeed, advocates asked how capacity could be defined, emphasising the unique nature of an individual's tolerance and resistance to alcohol: 'I just don't see how one could. I just don't see how you could because how would you say this is capacity?' (barrister 11). The issue of being unable to define 'capacity' reflects the arguments that appeared in response to the Office of Criminal Justice Reform's consultation on whether capacity should be defined in legislation. ${ }^{38}$ Also, echoing the debates in Bree, it was stated that different individuals have a greater or lesser ability to cope with alcohol and that the law cannot legislate on a specific point when all persons may be deemed incapable of choosing to have sex, due to individual difference in alcohol tolerance. Indeed, due to the unique and variable nature of an individual's ability to cope with alcohol it was argued that jurors should continue to apply their 'common sense' (barrister 3) to each individual case, as opposed to codifying the capacity term in law. It is possible to surmise that such difficulties in the framing and defining of the term underpin why the most recent edition of the Crown Court Bench Book, which sets out illustrative jury directions, does not provide further clarification on the meaning of capacity. ${ }^{39}$

Whilst the majority of advocates argued that the law was not capable of defining capacity, the lack of an 'objective standard that you can put the person against and say at that point, they're so drunk that they cannot consent' (barrister 12) was still seen to be a key problem when prosecuting alcohol-related rapes. The difficulties that jurors were perceived to experience in relation to this latter point directly reflect the

37 Home Office, Sexual Offences Act 2003: A Stocktake of the Effectiveness of the Act since its Implementation (London: Home Office, 2006).

38 Office of Criminal Justice Reform, above n. 15.

39 Judicial Studies Board, The Crown Court Bench Book: Directing the Jury (Judicial Studies Board: London, 2010) 371-6. 
concerns voiced in the academic literature which argue that the 2003 Act provides insufficient guidance on how to interpret levels of capacity and an individual's ability to choose freely. ${ }^{40}$ As stated, this situation is not currently clarified through an accompanying Bench Book direction. Whilst recognising the difficulty of defining the capacity term, barrister 14 felt it should be elaborated upon further in legislation through a simple definition which drew out the key concepts and actions associated with the construct, to help alleviate the current ambiguity. The divergence in opinion here may relate to barrister 14's more recent exposure to rape cases. Whilst having an extensive history of trying sex offences, barrister 14 had only recently started to defend in rape trials. Barrister 14 may consequently have been less exposed to the significant legislative changes that have taken place in relation to rape over the last several years and may therefore not be as 'cynical' (barrister 8) about the impacts of recent legislation as more experienced advocates reported themselves to be.

The general consensus, however, was that the lack of objective standard that could be drawn upon to highlight the point whereby an individual looses the capacity to choose, was not considered to be something that could be resolved through further legislation that focused on defining capacity. Indeed, several barristers emphasised that there had been too much legislation in recent years and that defining legal concepts could be both 'patronising' (barrister 1) and push jurors towards a specific viewpoint which was not necessarily their own. Barristers also argued that a further definition would not be useful because jurors would continue to make 'human judgements' (barrister 4) about cases based on the acceptability of the complainant's and defendant's drunken behaviour. In addition, barristers frequently surmised that jurors do not apply judicial directions in a mechanistic way, as will be discussed in further detail below. It is therefore perhaps unsurprising that the majority of advocates did not wish to see additional definitions being introduced into the legal arena.

\section{Too drunk to consent? The use of the incapacity argument}

Despite barristers' noted concerns surrounding the point of incapacity, the majority of advocates argued that they did not frequently see rape cases where the prosecution's case would be based on the complainant having not had the capacity to consent to sex. Instead, cases were typically reported to proceed to trial on the basis that sex was nonconsensual: 'If I was prosecuting a case and I felt that my complainant was so drunk so as to not be able to give informed consent, I certainly would be using that. But I've personally not witnessed and not heard of a case' (barrister 14).

The infrequent use of this argument may be because those cases that are marked by a lack of capacity are less likely to meet the Crown

40 C. Elliott and C. de Than, 'The Case for a Rational Reconstruction of Consent in Criminal Law' (2007) 70 MLR 225; Elvin, above n. 36; Tadros, above n. 34; Temkin and Ashworth, above n. 9. 
Prosecution's evidential test necessary to proceed to trial. Indeed, several barristers argued that cases in which the complainant was very drunk are likely to involve extreme memory impairment which will impact on the ability to build a case that is likely to get a conviction in court. As such, these cases may less frequently enter the court system. In addition, complainants were often noted to 'play it down' (barrister 11) when it came to articulating the amount of alcohol they had consumed prior to rape. This underreporting may also go some way towards explaining why the incapacity line of questioning was not deemed relevant, and pursued further. It may also reflect the somewhat confused nature of capacity and the inability to define clearly the point of incapacity. Advocates may therefore opt to avoid this problematic area of the law and proceed to trial on the basis that sex was non-consensual.

At this juncture it is perhaps worth reflecting on the argument presented by Wallerstein, in a previous edition of this journal. To recap, Wallerstein argues that a drunken consent should not be recognised as a legal consent, due to various normative and public policy factors. ${ }^{41}$ Given the barristers' experiences that complainants, and indeed defendants, tend to underplay their level of drunkenness, it can perhaps be surmised that if the law is altered to embody the notion that 'a drunken consent is not consent', this may bring about a significant change as complainants may feel less reticent to speak about their intoxicated state and the impact this had upon their behaviour. Moreover, if evidence of a loss of memory is considered as potential evidence that the consent was a drunken consent and therefore not legally valid, this may also assuage any fears the Crown Prosecution Service have with regard to having sufficient evidence in such cases. Whilst the Crown Court Bench Book does not acknowledge the perspective of Wallerstein, it does recognise that the trauma of experiencing rape may have a detrimental impact on the memory of the complainant. The direction sets down that any inconsistency in a complainant's testimony should not be taken to indicate, necessarily, that the allegation was false. ${ }^{42}$ It is, perhaps, disappointing that the Bench Book fails to provide a direction to the effect that an inability to remember whether one consented to, or engaged in a sexual encounter due to one's intoxicated state, could be seen as evidence that the complainant was duly incapable.

Various factors suggested that barristers would not be accepting of Wallerstein's perspective. As will be discussed, it was clear that barristers were wary of provisions which reduce the role of the jury, with judges being considered similarly reluctant to trespass into what is considered the province of the jury. Under Wallerstein's suggestion, if the jury accepted that the complainant was drunk, they would, by law, have to consider that her consent was invalid. Although a finding that a woman was drunk would not automatically lead to a conviction, as a jury would still have to consider whether the defendant had sufficient mens rea, the role of the jury would be much diluted to that at present where the

41 Wallerstein, above n. 17.

42 Judicial Studies Board, above n. 39 at 361-2. 
jurors are left to decide whether, despite her drunken state, the complainant retained the capacity to consent. Similarly, many of the barristers noted that, in their opinion, juries generally recoiled from being pushed into a verdict. For example, barrister 1 stated: 'But jurors ... juries don't like being pushed. Certainly in [the study area] they don't. And the more you push them in one direction, the more they'll push in another direction.' Barristers may also be similarly reluctant to adopt the Wallerstein approach due to their noted views on alcohol disinhibiting an individual's behaviour and this supposed reality being one of the primary possibilities that jurors consider in their evaluation of the case. That is, the key factors jurors were believed to weigh up in their interpretations of cases included whether the sex was non-consensual or the byproduct of drunken disinhibition, which was later regretted and reclassified as non-consensual. It is legitimate to suggest that adopting an approach which assumes a drunken consent is legally invalid will be perceived to push the balance too far in favour of the complainant. Indeed, barristers stated that many of the 2003 Acts provisions were unduly pro-prosecution and served to disadvantage the defendant. Hence, revising the law to render a drunken consent invalid may not lead to more just outcomes or protect the 'negative' sexual autonomy of a complainant. ${ }^{43}$ Moreover, as will be examined in the following section, there is a distinct difference between the letter of the law and the law in practice.

\section{Barristers' perspectives on the 'consent presumptions'}

As previously noted, the consent presumptions were introduced in an attempt to 'strike the right balance' between the complainant and the defendant and to '.. send a clear signal to the public about the circumstances in which sexual activity is likely to be wrong' and will therefore 'encourage genuine victims to bring cases to court' ${ }^{44}$ Academic opinion, however, has been far less positive about the introduction of the presumptions, and the decision to construct s. 75 as an exhaustive list has been subject to criticism. ${ }^{45}$ Barristers were therefore asked to comment on the frequency of presumption use at trial. They were also asked specific questions in relation to presumption s. 75(2)(f), a presumption that specifically relates to rape cases involving intoxication, in order to address the ways in which this provision was being interpreted and applied by advocates in practice. These issues were addressed to gain a more complete picture of how the 2003 Act had impacted on the prosecution of alcohol-involved rape cases and to address whether provisions aimed at assisting in the prosecution of such cases were in fact impacting as anticipated.

43 On negative sexual autonomy, see Wallerstein, above n. 17 at 330-1.

44 Home Office, above n. 6 at para. 32 .

45 Temkin and Ashworth, above n. 9 at 338-40. 


\section{Presumption frequency and rebuttal evidence}

Considering the heavy workload of the barristers interviewed, one would perhaps assume that the majority of advocates would have had experience with cases in which the presumptions had arisen. In fact, very few had worked on cases in which either the evidential or conclusive presumptions had been incorporated into a trial. Indeed, when asked about the application of the presumptions there was unanimous agreement that they were 'rarely' (barrister 9) used and that they may intentionally be 'side-tracked' (barrister 10) and 'circumvented' (barrister 14) in cases. Indeed, one barrister talked about physical violence having been a feature of a rape they defended but commented that the judge had intentionally avoided using the violence presumption (s. 75(2)(a) and (b)). There was a general consensus that those involved in rape cases - the prosecutor, barrister and judge alike-would try to avoid using the presumptions as much as possible. Barrister 1 argued that judges try very hard now to keep their presumptions to a minimum ... [and] tend to have broadly similar view [to the barristers] which is don't overload the jury with either too many counts or too much law'. It was argued that judges did not like the presumptions due to the perception that they amounted to the judge 'trespassing into the jury's ... domain' (barrister 2). Furthermore, it was argued that the presumptions complicated the trial process and overloaded the jury with additional, and complicated, legal concepts. Again, in light of jurors' perceived difficulties with applying and following legal directions and definitions, this is perhaps unsurprising: '. . I I think judges shy away from them [the presumptions] . . . because they want ... I think they're reaching for clarity and making things straightforward for the jury' (barrister 10). These findings again reflect the conclusions of the Home Office stocktake that suggested the conclusive and evidential presumptions had infrequently been utilised thus far, and have consequently had little impact on the prosecution of rape cases. ${ }^{46}$

When asked their opinions on the presumptions, certain barristers argued that they were patronising and that it was not necessary for them to have been specifically written into the law. Indeed, barrister 3 stated, 'I think all the presumptions do is state the ... obvious ... I don't see sometimes how all these very clever amendments to very good oldfashioned laws make the system any better'. Whilst several advocates disagreed with this viewpoint and felt that it was useful to have a set list of circumstances in which consent was likely to have been absent, these barristers still suggested that jurors would be intelligent enough to realise that if someone was detained, asleep or threatened with violence, they would be unlikely to have consented to the intercourse. For example, barrister 4 argued:

You know, do people need to have pointed out to them that ... she's not really giving consent ... that if he's spiked her drink ... that she's not really consenting? I don't think people are that daft really, you know, that 
they have to be given a definitive list . . . did they really need it pointing out to them?

Certain advocates also felt the presumptions swung the balance too far in favour of the prosecution and had been specifically included for the purpose of increasing the conviction rate. However, when asked about the amount of evidence necessary to rebut the evidential presumptions barristers generally agreed it was 'not a lot' (barrister 9) and that 'I can't think of a case in which . . . an evidential burden wouldn't be discharged by a defendant' (barrister 8). The defendant's own testimony or ability to 'float the contrary possibility' (barrister 10) and suggest that sex was consensual, was often perceived sufficient. This finding provides empirical support for Finch and Munro's speculation that the amount of evidence necessary to rebut the evidential presumptions may not be substantial. ${ }^{47}$

Although the 2003 Act does not specifically state whether it is the judge or jury who decides whether a presumption has been rebutted, the Judicial Studies Board direction is written with the assumption that it is the judge who so decides and academic commentary also supports this perspective. ${ }^{48}$ However, there was some confusion in relation to this specific point with advocates seeming to believe that it was for the jury to decide. For example, barrister 10 stated: 'there is often evidence [to rebut the presumption], even if it's from the defendant himself, and the jury will latch on to that'. Furthermore, barrister 12 argued '. . . it's just credibility ... it really does very much come down to who the jury believe'.

Overall, there was a general consensus, especially amongst the more experienced barristers, that the presumptions have not only been overwhelmingly unsuccessful: 'I don't think they've helped in the slightest' (barrister 3) and 'I don't think that presumptions really have that much impact on the whole thing' (barrister 12); but also that they are considered to be somewhat of an obstacle and something to be avoided, as opposed to a measure which has helped to achieve justice.

\section{Presumption s. 75(2)(f): drink-spiking and involuntary intoxication}

To recap, s. 75(2)(f) is specifically concerned with involuntary intoxication arguing that consent and belief in consent will be presumed absent if 'any person had administered to or caused to be taken by the complainant, without the complainant's consent, a substance which, having regard to when it was administered or taken, was capable of causing or enabling the complainant to be stupefied or overpowered at the time of the relevant act'. Whilst barristers considered this a logical presumption to include within s. 75 , it was not perceived to be especially radical, but rather seen as codifying what existed within the pre-2003 law. Significantly, no barrister had experience of using this presumption although one barrister was anticipating it to be a potential feature in a

47 Finch and Munro, 'Intoxicated Consent', above n. 34

48 See R. Card, Sexual Offences: The New Law (Jordan Publishing: Bristol, 2003) 42; R v Hendy (1989) 88 Cr App R 187. 
future case. In light of the infrequency with which the presumptions were used generally, this may not be especially surprising. However, a frequent argument for its lack of application was that drugs such as Rohypnol and GHB (those typically associated with drug-facilitated sexual assault) passed quickly through the system. When complainants delayed reporting a rape or indeed reported, but then went through the process of outlining their complaint, going to a rape unit and waiting to see a doctor, the substance was likely to have passed through the individual with there no longer being an evidential basis on which s. 75(2)(f) could be applied. Due to this perceived reality it was surmised that the presumption would 'arise very infrequently in trials' (barrister 1) with barrister 6 also observing: 'I mean I think it's absolutely right, having that presumption. Although, as I say, I think the incidences where it actually occurs are few and they're not at the heart of the problem with the rape statistics.'

Section 75(2)(f) was conceptualised and understood by barristers as firmly covering the classic instance of a sedative drug being administered covertly into a complainant's drink. Broader-scoped circumstances which may be applicable under the presumption were not conceptualised by advocates and taken forward. For example, barristers did not know, or were not making use of, the distinction between the terms 'administered' and 'caused to be taken'. As emphasised by Finch and Munro 'caused to be taken' suggests an activity of broader application than 'administration' which may cover instances of less surreptitious administration of an intoxicant such as encouragement, social pressure and the intentional buying of double measures instead of single. ${ }^{49}$ In addition, the range of situations encompassed by the term 'without the complainant's consent' could include the circumstance whereby an already drinking complainant unknowingly consumes higher quantities of alcohol than intended, due to the defendant's misrepresentation. ${ }^{50}$ When questioned on s. 75(2)(f) several barristers agreed that it could also be applied in circumstances when an individual's drink has been spiked with additional alcohol, when a complainant was being bought double or triple measures when she believed them to be singles and when the complainant's consumption could be demonstrated to be nonconsensual and due to some form of deception. Whilst accepting the possibility of such uses the presumption was not currently working or being applied in these ways with one highly experienced barrister arguing, 'I've never seen it used like that' (barrister 12). When asked to speculate on why the presumption had been drafted in the way it had, barristers generally viewed it as having been devised to cover all bases and prevent appeals, as opposed to cover the aforementioned circumstances.

In light of these arguments it may be suggested that s. 75(2)(f) has done little to improve the prosecution of alcohol-involved rape and that the presumption itself is being interpreted narrowly as covering the 
classic instance of drug-facilitated sexual assault. Again, the presumption may not be operating in broader ways due to the previously discussed playing down of alcohol by complainants prior to a rape. A complainant might not include within her statement details of her drinks having been bought by a defendant or, indeed, may modify the amount of beverages that were purchased. In the absence of complainants having the same rights as defendants to consult on 'tactics' (barrister 14) with the prosecutor, it is easily understood how the possible issue of a defendant surreptitiously buying the complainant a triple measure for the purpose of procuring sex is never unearthed and s. $75(2)$ (f) not considered.

\section{Jury behaviour: legal directions and definitions- helping or hindering the jury?}

Barristers talked extensively about the introduction of additional directions and definitions since the enactment of the 2003 Act. Jurors' abilities to comprehend alcohol-relevant legal directions were considered along with the eventual application of such directions in the trial context. Advocates frequently argued that the directions given by judges in relation to consent, capacity and the presumptions were not always perceived to be applied by jurors in a 'mechanistic' (barrister 11) way to help guide their assessments of guilt and innocence. Instead, it was frequently argued that jurors make an assessment of the witnesses based on the way they present themselves and their evidence in court, on their perceived likability, 'on a gut reaction of the facts' (barrister 9) and also on how the juror themselves believes they would have behaved in the given circumstances. The majority of barristers felt this was representative of jurors' decision-making processes and that their likes and dislikes, 'who they believed' (barrister 8) and their personal convictions about the complainant and defendant were far more relevant influences on their decision-making than legal instructions. This clearly has concerning implications if verdicts are being based on personal judgements and factors external to the evidence presented:

... it depends on the likeability of the defendant. There are some defendants um who are inherently unlikeable and you know they're gonna have to do a hell of a lot to make a jury accept what they're saying. Um there are some who look angelic, who may be as guilty as can be. But I'm sure jurors are happy to dispense with err presumption ... Because trials are ordinary people dealing with ordinary people, and their likes and dislikes um can't be left at the door. (barrister 1)

Whilst talking about jury directions, the point was frequently made that there are the increasing number of directions and definitions that judges are required to provide in relation to consent, capacity and the presumptions, which often appear to be designed to 'push' (barrister 8) a jury down the road to conviction. A number of advocates did not think this was helpful and actually felt that it could be detrimental to the trial process in light of an individual's innate resistance towards being told how to behave. Indeed, it was felt that if a judge tells a jury, or tries to 
guide a jury into a conviction, you've got . . . that's your best chance of being acquitted' (barrister 13). Failure to utilise legal instruction fully may also be related to certain advocates' perceptions that directions and definitions were often too complex for jurors to understand and meaningfully apply. By their very nature, legal directions and definitions were viewed as either complex or ambiguous. For example, the previously discussed direction on capacity given in the case of Bree concluded that 'a drunken consent is still consent', ${ }^{51}$ but that if the complainant had 'temporarily lost her capacity to choose', she could not be deemed to be consenting. ${ }^{52}$ Barristers reflected this idea of direction as being unhelpful, rhetorical and confusing, and felt that it was essential to have 'clarity' (barrister 10) and to 'keep the law simple and to the point' (barrister 8) if it was to be understood and effectively applied.

The suggestion that jurors do not fully understand judicial direction is supported by the recent Ministry of Justice funded project that analysed 68,000 verdicts, questioned jurors and staged simulation trials. The study identified that over two-thirds of jurors in criminal trials did not wholly understand the directions they were given. ${ }^{53}$ These findings also support the arguments raised in the Home Office stocktake of the effectiveness of the 2003 Act so far. ${ }^{54}$ Here it was suggested that the statutory definition of consent had made little difference to the pursuit of rape cases through the criminal justice system due to the definition being poorly understood by both practitioners and the general public. These suggestions also echo the findings from the mock rape trials carried out by Finch and Munro. ${ }^{55}$ When mock jurors were asked to address whether the complainant had the freedom and capacity to consent to sex, jurors had difficulty interpreting and applying the definition. This resulted in a flexible legal test where jurors would deviate in their views on the point of incapacity.

\section{The need for further reform?}

\section{Additional presumption to cover the instance of extreme drunkenness}

In light of the above considerations it is perhaps unsurprising that no barrister saw the benefit, or the legal legitimacy, of having an additional evidential presumption that covered the instance of being too affected by alcohol to give free consent. Indeed, it was argued that a further presumption or definition would add additional confusion to the law. This again reflects the arguments provided in response to the Office of Criminal Justice Reform on whether the law in this area should be modified. ${ }^{56}$ Barristers' additional reasons for not incorporating such a presumption included that it would have little impact due to the ease with which it could be rebutted and that it would be exceptionally

$51 R$ v Bree [2007] 2 Cr App R 13 at [32].

52 Ibid. at [34].

53 C. Thomas, Are Juries Fair?, Ministry of Justice Research Series 1/10 (Ministry of Justice: London, 2010)

54 Home Office, above n. 37.

55 Finch and Munro, 'Juror Stereotypes', above n. 3.

56 Office of Criminal Justice Reform, above n. 15. 
difficult, like capacity, to articulate the point of extreme drunkenness in law. Again, the point was made that jurors decide cases based on who they believe and like, not on legal instructions and its inclusion would therefore be somewhat redundant. Again, certain barristers felt that such a presumption would push the balance too far in favour of the complainant and that this was at odds with an adversarial legal system. The point was also raised that the law is not well placed to moralise on the ethics of having sex when individuals are extremely drunk and that this is as issue which needed to be addressed at a societal level through education, not additional legislation. It was also stated by several barristers that it was not necessary to have such a presumption written into the law because if extreme drunkenness was a feature of a rape, the judge would typically direct on this issue and state that if the complainant was so drunk that she could not rationally have made the decision, that would not be consent.

\section{Further legal reform in the area of voluntary intoxication}

Participants in the study did not feel there was a need for further reform within the area of voluntary intoxication and rape. Indeed, barristers perceived any future legal changes as a negative which would inevitably include further instructions, directions and the additional defining of legal concepts. Advocates felt that any future changes should focus on reducing or simplifying current directions. Again, one barrister argued that legal reform was not a cure-all measure and that legal changes would only be effective in a society which respected other individuals and where individuals took responsibility for their actions. It was acknowledged that society does not always operate with respect and that social education was also necessary to create a fertile environment in which legal procedures could optimally impact. For this barrister, the additional changes that needed to be brought about involved societal changes which encouraged individuals to think and act ethically, even if drinking to excess. This latter point again corresponds with the suggestions made in the Home Office stocktake. ${ }^{57}$

The difficulties inherent in establishing innocence and guilt in an acquaintance rape situation where independent evidence is lacking and alcohol has impacted on recollections were noted by barristers. They commented that no additional reform in the area of intoxication could help resolve these fundamental problems which made it especially difficult to get convictions in alcohol-related rape cases. In addition, it was felt that no further reform, direction or definition could 'make jurors think what they don't think' (barrister 3) and that no further 'tinkering' (barrister 7) with definitions would be sufficient to control for the influence of jurors' perceptions and judgements:

Um without sounding too cynical, I'm not sure there's more that you can do. Because you're gonna keep coming back to the point that a jury are always gonna assume ... and probably right, people to an extent are disinhibited when they're drunk, but on both sides. Um I'm trying to think 
if anything . . . I don't think there's anything that comes to mind that I could see ... I mean, obviously if anyone's suggested anything, I'm sure they'd be more creative than I am. But no, as a bit of a . . . as a criminal hat, I think everything comes back to perceptions, what the jury make of it and whether they think the conduct was acceptable or not. (barrister 8)

The new edition of the Crown Court Bench Book acknowledges aspects of the above statement and the potential for juror prejudice to impact in rape cases by providing illustrative directions to deal explicitly with 'mistaken assumptions'. The Bench Book details nine problematic circumstances whereby the jury may approach the complainant's evidence from a biased or sceptical viewpoint. These incorporate the assumption that '[t]he complainant got drunk in male company; therefore he/she must have been prepared for $\operatorname{sex}^{\prime} .^{58}$ The relevant illustrative direction includes the following paragraph:

A woman clearly does not have the freedom and capacity to make a choice if she is unconscious through the effects of drink and sleep. There are, of course, various stages of consciousness from wide awake to dim awareness of reality. In a state of dim and drunken awareness you may or may not be in a condition to make choices. You will need to consider the evidence of the complainant's state and decide these two questions: Was she in a condition in which she was capable of making any choice, one way or another? If you are sure she was not then she did not consent. If, on the other hand, you conclude that the complainant chose to agree to sexual intercourse, or may have done, then you must find the defendant not guilty. ${ }^{59}$

This paragraph is interesting to note on several counts; clearly, capacity remains integral to the offence of rape in the above circumstance, despite the jury being provided with no further elaboration on the nuances of capacity, how to evaluate fully its presence or absence or its impact on an individual's ability to choose. Whilst this absence of additional elaboration appears to coincide with the barristers' perspectives and the view that juries should not be provided with further direction on this point, they nevertheless still felt it was a problematic concept which juries struggled to interpret. Thus, it can perhaps be argued that the term 'capacity' remains problematic and when it is a central feature of the crime of rape which jurors are required to consider, further thought on how 'capacity' should be defined and applied in cases involving voluntary intoxication is required. Secondly, the first sentence of the paragraph appears to contradict s. $75(2)(d)$ which stipulates that if the complainant is unconscious, lack of consent will be presumed, but not conclusively. This discrepancy may again cause further problems, ambiguity and uncertainty for jurors in rape cases.

\section{Conclusion: study implications}

The research detailed above has highlighted that certain provisions introduced by the 2003 Act are not being utilised in a way that was

58 Judicial Studies Board, above n. 39 at 365.

59 Ibid. 
initially intended by the government. Indeed, the presumptions appear to be infrequently incorporated into trials despite the possible existence of the given circumstances. Section 75(2)(f) specifically has been interpreted and applied very narrowly and cases that could potentially fall within its usage are not at present doing so. This raises serious questions over whether these provisions have met their intended aims of improving the prosecution of alcohol-involved rape. The study shows that, for some advocates, there was a level of unfamiliarity with certain provisions of the 2003 legislation and that awareness raising to tackle these gaps, as well as to encourage the more dynamic uses of s. 75(2)(f), should be considered; only then will the presumptions be likely to impact optimally.

As discussed, there were examples of cynicism amongst advocates in terms of the impact and logic of the 2003 legislation. There was a clear perception that jurors were being over-directed and that directions and legal definitions were not always understood and applied by jurors mechanistically. It was argued that the law must be clear and concise if it is to be effectively utilised. Consequently, advocates were reluctant to see additional legislative changes being brought in to the area of voluntary intoxication and rape, including a general reluctance towards the legislative defining of capacity. Indeed, the point was made that too much legislation has been introduced over the last several years, that legislation has become politicised and that legal reform was not a cureall solution. Education and awareness at a societal level was also deemed paramount in order to allow legislation to impact optimally. As a result, barristers felt that the way to tackle the issue of rape following voluntary intoxication was to promote societal messages that dispel rape myths, which highlight the importance of acting ethically when drinking, of acceptable behaviour and social responsibility on the part of men, as well as women. Barristers felt that such messages should be built into the educational curriculum and that this was the integral background to developing a society that could negotiate sexual consent and openly discuss sexual issues, expectations and intentions. In practice, attitudinal change may be difficult to foster, particularly because attitudes around the consumption of alcohol are embedded within complex social beliefs which link alcohol use with sex. The promotion of messages that convey the unacceptability of using alcohol to procure sex, that question the morality of having sex with an intoxicated person and which encourage responsible consumption need to recognise the influence of these beliefs. In the mean time, complainants experience a system which does not serve them adequately in all instances.

Furthermore, barristers highlighted that jurors' perceptions and personal convictions about complainants and defendants were deemed more relevant influences on their decision to convict or acquit in rape cases than legal instruction. It is clear that personal convictions and speculations allow for the inclusion of factors external to the case and evidence to be drawn upon in the formation of verdicts. The prevalent attitude that women 'cry rape' following consensual sex when alcohol is involved compounds the problem of receiving a verdict based upon 
objectivity. Additional public awareness around the provisions of the 2003 Act seems necessary to help enlighten the lay public in terms of their understanding of sexual offences and to make clear what is acceptable and unacceptable sexual behaviour. Although such education would not eradicate the problems associated with the lack of supporting evidence that surrounds rape cases, the difficulty of meeting the burden required to convict of rape and the inconsistencies in account that may result as a consequence of the impacts of alcohol on memory, it may go some way towards reducing jurors' potential for basing their decisions on their personal convictions and assumptions about the principal witnesses. 